4-19-2021

\title{
A Patient-Centered Study Examining Self-Identification of Mental Health Challenges Among Female Military Officers
}

Rosellen Roche

Joel Manzi

Katelyn Bard

Follow this and additional works at: https://aah.org/jpcrr

Part of the Community Health Commons, Military and Veterans Studies Commons, and the Women's Health Commons

\section{Recommended Citation}

Roche R, Manzi J, Bard K. A patient-centered study examining self-identification of mental health challenges among female military officers. J Patient Cent Res Rev. 2021;8:134-9. doi: 10.17294/ 2330-0698.1776

Published quarterly by Midwest-based health system Advocate Aurora Health and indexed in PubMed Central, the Journal of Patient-Centered Research and Reviews (JPCRR) is an open access, peer-reviewed medical journal focused on disseminating scholarly works devoted to improving patient-centered care practices, health outcomes, and the patient experience. 


\title{
A Patient-Centered Study Examining Self-Identification of Mental Health Challenges Among Female Military Officers
}

\author{
Rosellen Roche, MD, PhD, Joel Manzi, BS, BA, Katelyn Bard, BS \\ Department of Primary Care, Ohio University Heritage College of Osteopathic Medicine, Cleveland, $\mathrm{OH}$
}

\begin{abstract}
Due to the expansion of leadership roles in the military for women, female military personnel now face stressors equal to, and yet unique from, their male counterparts. This pilot study surveyed 73 female U.S. Army officers regarding their experiences of leadership and mental wellness within the military. A mixed-methods survey was distributed via 2 private Facebook groups for female Army officers following an anonymized convenience sampling. This anonymous, patient-centered protocol was used to protect against known stigma surrounding disclosing mental health concerns in the military. Respondents were asked a series of questions including perceived mental health status and access to behavioral health services. Most respondents reported feelings of stress related to their roles as officers (86.6\%). Selfreported feelings of anxiety (83.6\%) and depression (65.7\%) were high. In contrast, only $30.1 \%$ had ever received a formal diagnosis of anxiety or depression by a mental health professional. Our survey confirmed a large percentage, $65.7 \%$ of respondents, reported avoiding mental/behavioral health services. Female military officers are able to recognize their feelings as symptoms of anxiety and depression; however, many take active steps to hide these symptoms from their family members and senior officers and avoid seeking professional care. (J Patient Cent Res Rev. 2021;8:134-139.)
\end{abstract}

Keywords mental health; military and veterans studies; women's health; self-reporting; anxiety; depression

$\mathrm{W}$ ith the official inclusion of female service personnel in combat occupations in 2013, women now heroically serve in integrated units across the U.S. military. ${ }^{1}$ Rising in rank and number, women are increasingly occupying leadership roles within the military hierarchy, with nearly $18 \%$ of all officer positions held by women. ${ }^{2}$ As a result, the needs of military personnel returning home from duty are changing and reflect a diversifying military.

While the mental health of military personnel has been an area of prominent research, the experiences of female soldiers and veterans were notably absent from early inquiries. As researchers have noted, psychological distress, disease, and response to treatment varies greatly by gender. ${ }^{3,4}$ Following suit, researchers have only recently begun to explore the intricacies of the female military experience. ${ }^{5-10}$ Intertwined with the known traumas of wartime exposure and postdeployment readjustment, women face the added social and health challenges of

Corresponding author: Rosellen Roche, $\mathrm{MD}, \mathrm{PhD}$, Ohio University Heritage College of Osteopathic Medicine, 4180 Warrensville Center Road, Cleveland, OH 44122 (Rocher1@ohio.edu) military sexual trauma, marital problems, and returning to mother and caregiver roles. ${ }^{11-15}$

In light of military deployment, the stress-response patterns for men and women have been shown to differ significantly. ${ }^{16}$ The impact of these stress responses can manifest in a variety of mental health conditions. Whereas male soldiers are more likely to abuse alcohol, female soldiers have been shown to be more likely to experience depression and self-harm. ${ }^{17}$ While on deployment, female soldiers have been found to have higher rates of suicide. ${ }^{18}$ Upon return, rates of posttraumatic stress disorder, anxiety, and depression, among other mental health conditions, are more frequently reported by female service members. ${ }^{5,10,14,19-21}$

Although research has found that active-duty servicewomen were more likely to positively rate their health and access to health care than their comparable civilian counterparts, female veterans transitioning out of the military were more likely to rate their health status and access to care lower than civilian populations. ${ }^{22}$ In this transition from active-duty military service to veteran, there is a significant decline in physical health, mental health, and access to care. During times of active duty, women are entitled to full health benefits at military facilities through the TRICARE program. Once removed from active duty or reserve status, servicemembers 
transition to the Veterans Affairs health system, which historically has had low utilization among women. ${ }^{23-27}$

Active-duty female soldiers have rated their health highly in large population studies; however, studies indicate that their physical and mental health may not be as healthy as they report. ${ }^{6,8,10,16-18,21,22}$ The accuracy of health information, both mental and physical, is often reliant on who is reporting the data. ${ }^{28-30}$ Societal stigma surrounding mental health is prevalent in civilian culture, but the stigma surrounding mental health in the military is even more pronounced. ${ }^{31-33}$ Stigma and social pressures may dissuade a solider from reporting mental health concerns to military leadership, but she may report those concerns to an outside health provider, friends, or others who she feels will not impact her career in the military.

The goal of this pilot study was to explore the experiences of female U.S. Army officers and characterize their mental health challenges as described in their own words. Officers specifically were chosen because of the additional stressors related to military leadership responsibilities in combination with gender-minority status and familial responsibilities. As a relatively new area of research, a patient-centered approach adds significantly to the academic characterization the female soldier and veteran experience. With better understanding of this patient population's self-reporting behaviors, support services can be tailored to meet the needs of active-duty and veteran servicewomen.

\section{METHODS}

\section{Study Design}

Participation by military personnel in identifiable service-related mental health surveys is often low, or symptoms are falsely underreported. ${ }^{28}$ This is particularly so if respondents perceive their military status at risk..$^{34-36}$ In military populations, especially female military populations, mental health conditions are underreported and undiagnosed. ${ }^{37,38}$ To address this issue, our research team created a patient-centric survey that allowed female soldiers to indicate if they experienced feelings of mental distress, even if they had not received a formal diagnosis. The survey also was anonymously conducted outside of formal military command, which we believe increased confidence in participation and completion rates. Previous recent inquiries on this topic have used this style of survey, with favorable outcomes for both male and female servicemembers. ${ }^{39}$

As an anonymous survey, there was no mechanism to confirm mental health diagnoses with medical records, therefore results were dependent on self-reporting. To address this potential limitation, questions were asked regarding specific diagnoses by medical professionals. Other questions were then asked about symptoms and feelings regardless of professional diagnosis. With no official records available for comparison, it was important to the research team that patient-reported symptoms be captured by the survey instrument.

\section{Participants}

Participants for this study were recruited through postings on 2 private Facebook groups for female officers in the U.S. Army. These groups included active-duty servicewomen, Army Reserve members, and Army veterans. Facebook group administrators reviewed each prospective member request to verify current military or veteran status against the current Army Global Human Resource Network. Group administrators approved our recruitment posting after approval from the Ohio University institutional review board (IRB). Permission was then granted to post the advertisement for the survey to each group.

Membership across both Facebook groups totals approximately 11,000 . It is important to note that the number of actively engaged members varies significantly, as many are unable to $\log$ on during tours of duty. However, regarding the study's specific interest in those still on active duty, active-duty officer membership was high in both groups (over $80 \%$ ). To participate in this study, subjects had to identify as female, be either a current member of the Army or an Army veteran, and hold at least the rank of officer.

Of the 73 participating officers who completed the survey, 70 were on active duty and 3 were retired veterans.

\section{Procedure}

The survey consisted of 75 questions, with key questions determining applicability to each question set. Questions were asked in a multiple-choice fashion to ascertain the degree to which the respondent agreed with the posed statement. Strong agreement or disagreement prompted the participants to further elaborate in a qualitative free-text box. Responses in the free-text boxes were more prolific than anticipated - a total of 226 free-text responses were analyzed. Initial transcripts of responses were reviewed by 2 researchers and coded for significant themes using thematic analysis. A third researcher then recoded the transcripts independently. Any discrepancies in coding were resolved by consensus between all 3 researchers.

This report is part of a larger IRB-approved study on the experiences of female military officers in regards to command presence, caregiver stressors, support networking, and social media usage. 


\section{RESULTS}

\section{Quantitative Results}

This investigation set out to characterize the mental health challenges as described by female Army officers themselves. A total of 73 female officers completed the survey; not every question was applicable to nor answered by every participant. Throughout analysis an important trend emerged. When questioned if they had received a formal, professional mental health diagnosis, 28 of 68 respondents $(41.2 \%)$ indicated at least 1 diagnosis, and 11 of 68 respondents $(16.2 \%)$ had been formally diagnosed with both anxiety and depression. However, when directly asked if they experienced feelings of anxiety or depression, with or without a formal diagnosis, 56 of 67 respondents (83.6\%) self-reported anxiety and 44 of 67 (65.7\%) self-reported depression.

While mental health care services are included in military and Veterans Affairs benefits, these services are not always utilized. In our survey, 44 of 67 respondents $(65.7 \%)$ reported that they had actively avoided seeking mental health services due to their status in the military. Further investigation into these findings led to the emergence of several recurrent themes.

\section{Qualitative Results}

Out of 226 analyzed qualitative responses, two particularly strong themes emerged: 1) the role of the military as a hindrance to seeking treatment, and 2) how the dual role of caregiver and officer affects mental health. A sample of key illustrative comments for each theme is provided hereinafter.

\section{Female Military Officers Recognize Challenges to their}

Mental Health. Respondents were aware of the state of their mental health. This was especially so in connection with their roles as leaders in a military setting. Many noted they do not have formal diagnoses but recognized the signs and symptoms of depression and/or anxiety in their life. Example responses included:

"If I actually went to Army mental health providers, I'd probably be diagnosed with anxiety/depression."

"(Although not diagnosed) I know I suffer from anxiety and mild depression."

Tied to these feelings was the distinct challenge of their unique work environment.

"I have not been diagnosed, but I do have anxiety and depression. I have been in a toxic and bullied environment for 2.5 years, but I kept telling myself to stay strong."

"Over time, we are desensitized as we are expected to interact with peers as 'tough' and without emotion."
Another concerning issue connected to their roles as officers voiced by respondents was that utilizing mental and behavioral health services provided by the military would be detrimental to their careers as military officers. Respondents who had been diagnosed discussed avoiding seeking care within the military.

"I go off post to a therapist that I pay out of pocket for because the Army keeps saying it won't affect your clearance. It will."

Family Responsibilities Represent a Major Source of Stress Leading to Poor Mental Health. The dual burden faced by women officers in the military to maintain familial and domestic duties in addition to their professional ones represents a major source of concern. Several respondents found managing these competing duties to be challenging and often incompatible with a healthy mental status.

"[I] have to balance work, family, and self. Determining priorities should be easy, but it's challenging"

"My family has no idea [I am depressed]. They believe I am the most cheerful and enthusiastic one of us all."

It was reported that family members often bear the brunt of maladaptive behavior. Respondents connected their poor mood to relational stress. Multiple respondents noted that their partners, spouse, or significant other was not well equipped to handle their stress, depression, and/ or anxiety.

"I take my stress out on my significant other. I have to be 'on' at work so my spouse receives the brunt of my 'off.',

"It puts stress on us, and my husband doesn'tunderstand or know how to deal with it (nor do I)."

\section{DISCUSSION}

This pilot study is novel in both its target population of female military leaders and its first-person, patient-centered approach. It showed that female U.S. Army officers recognize feelings of anxiety and depression in themselves, whether they have had a formal diagnosis or not. Many, in fact, take active measures to hide these symptoms from their military colleagues and family members. Per our findings, female military officers are often acutely aware of the effects of their career and military status on their mental health. These women in leadership frequently stated that they avoided seeking professional care for fear of repercussions from the military.

Among survey respondents, $65.7 \%$ actively avoided seeking mental health care. Women participating in this study frequently highlighted concerns of repercussions from military leadership, loss of employment, and lack of available resources as reasons for avoiding care. These findings are consistent with other studies that have found 
female veterans have avoided seeking mental health care. ${ }^{40}$ Other researchers who focused on health care utilization among military personnel have found a lack of resources designed specifically for women, a knowledge deficit surrounding available benefits, and inconvenient access to services as motivations for avoiding care or seeking care elsewhere. ${ }^{24,27,41}$ Addressing these issues will be paramount if meeting the mental health needs of military women is to be achieved.

The negotiation of work-family dynamics was cited by many women in this study as a source of major stress. Though working in the military, often taking many years to achieve officer status, many traditional gender roles and expectations await these women when they return home. ${ }^{42}$ While there are many articles describing the stresses of "military wives" (ie, civilian women with male military spouses), ${ }^{43-47}$ there is limited literature describing the family life experience of a servicewoman as the spouse or partner in the military. ${ }^{15,38,42}$ As described by the women in our study, family responsibilities add another element of stress not experienced to the same extent as their male peers. While there are a variety of resources available for military families, they often focus on families with civilian female partners. An expansion of these family services to include support for servicewomen's families could serve to ameliorate some of the reported stress stemming from family responsibilities.

One strength of the study was its mixed-methods, patientfocused, anonymous data collection. The inclusion of self-reported data is vital to the patient-centered research approach. As seen in multiple studies, underreporting and inaccurate documentation of mental health in official military records is a serious issue..$^{35,48,49}$ By allowing military members to self-report their mental health concerns to a nonmilitary, nongovernmental source, a more accurate depiction of the mental health landscape can be obtained. As the survey was conducted by university-affiliated researchers, respondents were able to freely voice concerns regarding their experiences without fear of repercussions.

The sample size of this pilot is a study limitation. More respondents are necessary to provide more generalizable conclusions. As an anonymous data set, it was not possible to compare reported mental health diagnoses to official medical records. This is both a strength and limitation of the study because we believe the anonymous protocol promoted greater transparency and honesty in responses. A final limitation is that it was impossible to follow up with lengthier qualitative inquiry with these respondents due to the anonymity. Based on pilot results, additional quantitative and lengthier qualitative research is needed to further examine the mental health status of female military officers, the resources available to them, and the most successful mental health service delivery mechanisms.

While mental health issues of women in the military are multifaceted, there is no one better equipped to develop viable solutions than those at the center of this discussion. By creating an environment for patients to express themselves freely and without fear of repercussion, researchers can serve as valuable allies in developing patient-centered solutions. Continuing to directly engage patients in the research process is vital to understanding their struggles or systemic barriers to health and wellbeing and ultimately may provide solutions to some of the most pressing issues facing military servicewomen.

\section{Patient-Friendly Recap}

-Women in the U.S. military can experience different mental health stressors than their male counterparts.

- Authors surveyed members of two established Facebook groups for female military officers to learn about their mental health status and access to behavioral health services.

- Most respondents reported stress related to their roles as officers as well as feelings of anxiety and depression. However, less than one-third reported receiving a formal diagnosis by a mental health professional.

- Many female military officers take active steps to hide mental health-related symptoms from their family members and senior officers.

\section{Author Contributions}

Study design: all authors. Data acquisition or analysis: all authors. Manuscript drafting: Roche, Manzi. Critical revision: all authors.

\section{Conflicts of Interest}

None.

\section{References}

1. Roulo C. Defense Department expands women's combat role. American Forces Press Service. Published January 25, 2013; accessed April 4, 2019. https://www.jble.af.mil/News/ Article-Display/Article/257998/defense-department-expandswomens-combat-role/

2. U.S. Department of Defense. 2018 Demographics: Profile of the Military Community. Accessed April 4, 2019. https:// download.militaryonesource.mil/12038/MOS/Reports/2018demographics-report.pdf

3. World Health Organization Department of Mental Health and Substance Dependence. Gender disparities in mental health. Accessed May 9, 2020. http://www.who.int/mental health/ media/en/242.pdf 
4. Culbertson FM. Depression and gender. An international review. Am Psychol. 1997;52(1):25. CrossRef

5. Haskell SG, Gordon KS, Mattocks KM, et al. Gender differences in rates of depression, PTSD, pain, obesity, and military sexual trauma among Connecticut War Veterans of Iraq and Afghanistan. $J$ Womens Health (Larchmt). 2010;19:267-71. CrossRef

6. Seelig AD, Jacobson IG, Smith B, et al. Prospective evaluation of mental health and deployment experience among women in the US military. Am J Epidemiol. 2012;176:135-45. CrossRef

7. Jacobson IG, Donoho CJ, Crum-Cianflone NF, Maguen S. Longitudinal assessment of gender differences in the development of PTSD among US military personnel deployed in support of the operations in Iraq and Afghanistan. J Psychiatr Res. 2015;68:30-6. CrossRef

8. Kline A, Ciccone DS, Weiner M, et al. Gender differences in the risk and protective factors associated with PTSD: a prospective study of National Guard troops deployed to Iraq. Psychiatry. 2013;76:256-72. CrossRef

9. McGraw K. Gender differences among military combatants: Does social support, ostracism, and pain perception influence psychological health? Mil Med. 2016;181(1 Suppl):80-5. CrossRef

10. Polusny MA, Kumpula MJ, Meis LA, et al. Gender differences in the effects of deployment-related stressors and pre-deployment risk factors on the development of PTSD symptoms in National Guard Soldiers deployed to Iraq and Afghanistan. J Psychiatr Res. 2014;49:1-9. CrossRef

11. Katz LS, Bloor LE, Cojucar G, Draper T. Women who served in Iraq seeking mental health services: relationships between military sexual trauma, symptoms, and readjustment. Psychol Serv. 2007;4:239-49. CrossRef

12. Roche R, Manzi J, Bard K. A double bind for the ties that bind: a pilot study of mental health challenges among female US Army officers and impact on family life. J Veterans Stud. 2020;6(1):200-10. CrossRef

13. Hoge CW, Auchterlonie JL, Milliken CS. Mental health problems, use of mental health services, and attrition from military service after returning from deployment to Iraq or Afghanistan. JAMA. 2006;295:1023-32. CrossRef

14. Mattocks KM, Haskell SG, Krebs EE, Justice AC, Yano EM, Brandt $\mathrm{C}$. Women at war: understanding how women veterans cope with combat and military sexual trauma. Soc Sci Med. 2012;74:537-45. CrossRef

15. Gewirtz AH, McMorris BJ, Hanson S, Davis L. Family adjustment of deployed and non-deployed mothers in families with a parent deployed to Iraq or Afghanistan. Prof Psychol Res Pr. 2014;45:465-77. CrossRef

16. Adler AB, Huffman AH, Bliese PD, Castro CA. The impact of deployment length and experience on the well-being of male and female soldiers. J Occup Health Psychol. 2005;10:121-37. CrossRef

17. Jones N, Jones M, Greenberg N, Phillips A, Simms A, Wessely S. UK military women: mental health, military service and occupational adjustment. Occup Med (Lond). 2020;70:235-42. CrossRef

18. Street AE, Gilman SE, Rosellini AJ, et al. Understanding the elevated suicide risk of female soldiers during deployments. Psychol Med. 2015;45:717-26. CrossRef

19. Lehavot K, Goldberg SB, Chen JA, et al. Do trauma type, stressful life events, and social support explain women veterans' high prevalence of PTSD? Soc Psychiatry Psychiatr Epidemiol. 2018;53:943-53. CrossRef
20. Perlin JB, Mather SH, Turner CL. Women in the military: new perspectives, new science. $J$ Womens Health (Larchmt). 2005;14:861-2. CrossRef

21. Thomas KH, Albright DL, Shields MM, et al. Predictors of depression diagnoses and symptoms in United States female veterans: results from a national survey and implications for programming. J Mil Veterans Health. 2016;24(3):6-16.

22. Lehavot K, Hoerster KD, Nelson KM, Jakupcak M, Simpson TL. Health indicators for military, veteran, and civilian women. Am J Prev Med. 2012;42:473-80. CrossRef

23. Di Leone BAL, Wang JM, Kressin N, Vogt D. Women's veteran identity and utilization of VA health services. Psychol Serv. 2016;13(1):60-8. CrossRef

24. Hamilton AB, Frayne SM, Cordasco KM, Washington DL. Factors related to attrition from VA healthcare use: findings from the National Survey of Women Veterans. J Gen Intern Med. 2013;28(Suppl 2):510-6. CrossRef

25. Washington DL, Yano EM, Simon B, Sun S. To use or not to use. What influences why women veterans choose VA health care. J Gen Intern Med. 2006;21(Suppl 3):S11-8. CrossRef

26. Absher J. DoD, VA partner to offer women's health transition training. Military.com. Published July 19, 2019; accessed April 13, 2020. https://www.military.com/dailynews/2019/07/19/dod-va-partner-offer-womens-healthtransition-training.html

27. Bean-Mayberry B, Yano EM, Washington DL, et al. Systematic review of women veterans' health: update on successes and gaps. Womens Health Issues. 2011;21(4 Suppl):S84-97. CrossRef

28. Visco R. Postdeployment, self-reporting of mental health problems, and barriers to care. Perspect Psychiatr Care. 2009;45:240-53. CrossRef

29. Stone AA, Turkkan JS, Bachrach CA, Jobe JB, Kurtzman HS, Cain VS (eds). The Science of Self-Report: Implications for Research and Practice. Lawrence Erlbaum Associates; 2000 .

30. Calhoun PS, Sampson WS, Bosworth HB, et al. Drug use and validity of substance use self-reports in veterans seeking help for posttraumatic stress disorder. J Consult Clin Psychol. 2000;68:923-7. CrossRef

31. Acosta JD, Becker A, Cerully JL, et al. Mental Health Stigma in the Military. RAND Corporation; 2014.

32. Olmsted KLR, Brown JM, Vandermaas-Peeler JR, Tueller SJ, Johnson RE, Gibbs DA. Mental health and substance abuse treatment stigma among soldiers. Mil Psychol. 2011;23:52-64. CrossRef

33. Porter TL, Johnson WB. Psychiatric stigma in the military. Mil Med. 1994;159:602-5. $\underline{\text { CrossRef }}$

34. Hom MA, Stanley IH, Schneider ME, Joiner TE Jr. A systematic review of help-seeking and mental health service utilization among military service members. Clin Psychol Rev. 2017;53:59-78. CrossRef

35. Harris BR, Yu J. Service access and self-reporting: tailoring SBIRT to active duty military in civilian health care settings. J Soc Work Pract Addict. 2019;19:177-87. CrossRef

36. Britt TW, Sipos ML, Klinefelter Z, Adler AB. Determinants of mental and physical health treatment-seeking among military personnel. Br J Psychiatry. 2020;217:420-6. CrossRef

37. Brunner J, Schweizer CA, Canelo IA, Leung LB, Strauss JL, Yano EM. Timely access to mental health care among women veterans. Psychol Serv. 2019;16:498-503. CrossRef 
38. Wilson SR, Hintz EA, Wadsworth SMM, Topp DB, Southwell KH, Spoont M. Female U.S. military veterans' (non)disclosure of mental health issues with family and friends: privacy rules and boundary management. Health Commun. 2021;36:412-23. CrossRef

39. Jones N, Greenberg N, Phillips A, Simms A, Wessely S. British military women: combat exposure, deployment and mental health. Occup Med (Lond). 2019;69:549-58. CrossRef

40. Owens GP, Herrera CJ, Whitesell AA. A preliminary investigation of mental health needs and barriers to mental health care for female veterans of Iraq and Afghanistan. Traumatology. 2009;15(2):31-7. CrossRef

41. Kimerling R, Pavao J, Greene L, et al. Access to mental health care among women Veterans: Is VA meeting women's needs? Med Care. 2015;53(4 Suppl 1):S97-104. CrossRef

42. Huffman AH, Culbertson SS, Barbour J. Gender roles in a masculine occupation: military men and women's differential negotiation of the work-family interface. In: Mills MJ (ed). Gender and the Work-Family Experience: An Intersection of Two Domains. Springer International Publishing; 2015, pp. 271-89. CrossRef

43. de Burgh HT, White CJ, Fear NT, Iversen AC. The impact of deployment to Iraq or Afghanistan on partners and wives of military personnel. Int Rev Psychiatry. 2011;23:192-200. CrossRef

44. Lewy CS, Oliver CM, McFarland BH. Barriers to mental health treatment for military wives. Psychiatr Serv. 2014;65:1170-3. CrossRef
45. Murray KM. Emotion work on the home-front: the special case of military wives. ScholarWorks@UARK Theses and Dissertations. Published May 2011; accessed May 9, 2020. https://scholarworks.uark.edu/etd/75

46. Baptist JA, Amanor-Boadu Y, Garrett K, et al. Military marriages: the aftermath of Operation Iraqi Freedom (OIF) and Operation Enduring Freedom (OEF) deployments. Contemp Fam Ther. 2011;33:199-214. CrossRef

47. Balderrama-Durbin C, Snyder DK, Cigrang J, et al. Combat disclosure in intimate relationships: mediating the impact of partner support on posttraumatic stress. J Fam Psychol. 2013;27:560-8. CrossRef

48. Balani S, De Choudhury M. Detecting and characterizing mental health related self-disclosure in social media. In: $\mathrm{CHI}$ EA '15: Proceedings of the 33rd Annual ACM Conference Extended Abstracts on Human Factors in Computing Systems. Association for Computing Machinery; 2015, pp. 1373-8. CrossRef

49. De Choudhury MD, De S. Mental health discourse on reddit: self-disclosure, social support, and anonymity. In: Proceedings of the Eighth International AAAI Conference on Weblogs and Social Media. Association for the Advancement of Artificial Intelligence; 2014.

(C) 2021 Advocate Aurora Health, Inc. 